\title{
Meanings come in six
}

\author{
Andres Luure \\ Department of Philosophy, Tallinn University \\ Narva mnt 25, 10120 Tallinn, Estonia \\ e-mail: andresluure@gmail.com
}

\begin{abstract}
Though it seems to be reasonable to restrict the scope of semiotics, in order more completely to understand the semiotic phenomena it is necessary to specify all conceivable types of sign and meaning. The method of sextets is introduced that yields a uniform six-item structure of both general and special sign typologies. A general typology of signs and meanings in language and speech and a typology of referring are presented as the paradigms for the structure. In any sign typology in the framework of this structure, the categorisation of the unit of meaning is analogous to the first three items of the first paradigm. In any sign typology in this framework, the relation between the sign and the meaning is analogous to the relation of referring.
\end{abstract}

In the history of semiotics, the classification of signs has not been just a tool of application of the sign concept but also a means of a better understanding of the concept of sign itself, most notably in Charles Sanders Peirce's work ${ }^{1}$. In this article, an attempt is made to classify signs before defining the concept, in order for the classification to throw light on the concept itself. The underlying structure and the heuristic tool of both classification and definition is the sextet - a six-item set provided with a special structure ${ }^{2}$.

See especially Peirce 1992 [1868], Peirce 1998 [1903], Peirce 1998 [1908].

The concept of sextet has been explicitly introduced in Luure 2006a. In Luure 2001 and Luure 2006b there are examples of sextets, and in Luure 2002, threeitem fragments of sextets are used. 
Since Augustine ${ }^{3}$, the concept of sign has tended to be defined by generalising the signs used in human language and speech. Hence the problem arises where this generalisation is to end. There is no obvious limit to generalisation. There have been attempts to find natural boundaries of the semiotic realm; such boundaries can be based only on some sort of intuition. Semiologists are not willing to extend the semiotic realm beyond the human society. Eco (1979: 6) wrote: "By natural boundaries I mean principally those beyond which a semiotic approach cannot go; for there is non-semiotic territory since there are phenomena that cannot be taken as sign-functions". For him, those natural boundaries weren't far beyond human society. The biosemioticians lowered this 'semiotic threshold' to the boundary between life and the inanimate world ('the Sebeok's Thesis" ${ }^{\text {) }}$. Thomas A. Sebeok wrote for example: "[...] semiosis is what distinguishes all that is animate from lifeless. Before semiosis, there was information" (Sebeok 1986: 15). However, as such, information is just a further generalisation, and if we stop there then the genuine reason why seems to be not any natural boundary between sign-like things and other things but lack of purpose in generalisation. This is explicitly stated by Stjernfelt (2007: 217): "I have nothing against, to be sure, the idea that physical processes may be described in semiotic vocabulary, but I just do not see that vocabulary adds anything to our knowledge of such processes. Thus, they seem to constitute a sort of semiotic zero-case where semiotic terminology may be added or not."

In this article, we are trying to show how introducing sign types of apparently no use can be justified. Sextets of sign types will be introduced which always include 'zero-cases'. This allows us to extend the semiotic concepts in general and the specific sign typologies in particular to their maximum generality, and also to discover new aspects of the sign concept.

\section{The six basic types of signs}

We start our analysis of sign typology from the untechnical opposition of sign and meaning. At this stage, we intentionally avoid appealing to established semiotic theories because we are to extend their limits as

See Augustine 397: II.1.1.

4 See Kull, Emmeche, Favareau 2008: 42. 
to some aspects ${ }^{5}$. Our - however indeterminate - preliminary account is that the sign both uncovers and covers its meaning for the interpreter. The sign is to serve as an intermediate link that, as it were, contains some amount of the information the original source of meaning has to offer.

In cognition, any source of knowledge serves as a sign, knowledge being the knowledge of its meaning. The difficulty of knowledge arises precisely from the covering side of the sign, its uncovering being what renders knowledge possible. In order to uncover its meaning, the sign is somehow to betray its meaning in spite of its natural tendency to cover its meaning 'with its own body'. We have a scale of different degrees in which the sign reveals its meaning. We are seeking for a series of notches of this scale in order to base some typology of signs and meanings.

A central illustration is provided by the signs and meanings involved in language and speech.

The most commonly known example of a sign phenomenon in language seems to be the linguistic sign in Saussure's sense ${ }^{6}$. The linguistic sign is a psychological entity consisting of two psychological terms: the signifier and the signified (Saussure 1959 [1916]: 66$67)^{7}$. We are using this example as a familiar point to depart from. Though the ontological status of 'signs ${ }^{8}$ and 'meanings' is open so far, the mental account is appropriate as far as the 'sign'-'meaning' relation in language and speech always is mentally mediated (with the possible exception of the mystical relation; vide infra). In any case, both the linguistic sign and its two terms can be construed as

5 As to some other aspects, our examples may have a narrower scope than Peirce's theory of signs envisages.

6 "I propose to retain the word sign [signe] to designate the whole and to replace concept and sound-image respectively by signified [signifié] and signifier [significant]; the last two terms have the advantage of indicating opposition that separates them from each other and from the whole of which they are parts. As regards sign, if I am satisfied with it, this is simply because I do not know of any word to replace it, the ordinary language suggesting no other" (Saussure 1959 [1916]: 66-67).

See Saussure 1959 [1916]: 65-66: “[...] both terms involved in the linguistic sign are psychological [...]. [...] The linguistic sign unites [...] a concept and a sound-image."

8 Here and further, 'sign' and 'meaning', when in quotation marks, refer to our non-technical ad hoc expressions. 
categories (in the sense of the result of categorisation ${ }^{9}$ ). In our account, the 'sign' and the 'meaning' in Saussure's linguistic sign are located as follows: the signifier is the 'sign' and the linguistic sign is the 'meaning' ${ }^{10}$. Here, the 'meaning' is recognised in the 'sign', and this is the way the "sign" is perceived. The meaning is a category; the category 'gives the meaning' to the sign. In other words, the linguistic sign 'gives the meaning' to the signified. The examples of the linguistic sign can be extended to other linguistic units. What counts in the analogy is not the two-term structure of the linguistic sign but the relation between a (relatively) 'meaningless' term and the 'meaning'. So, grammatical categories provide another example of such a linguistic unit.

Another well-known example is referring ${ }^{11}$. In the context of referring, the 'meaning' (it is called reference) of a referring expression (a 'sign') is the thing the referring expression picks out. It transcends the linguistic realm, reaching the extralinguistic world. The things of the world are mediated by their mental counterparts (representations) in mental models. In contrast to the linguistic signs, the 'sign' and its reference are on an equal foot.

Let us compare the above two examples. The linguistic signs and their analogues remain in the realm of the properly linguistic. The meanings aren't directly connected with the extralinguistic reality. The referring relation brings us into the realm of speech, or language use. From the point of view of reference, the linguistic signs are clearly deficient because the linguistic 'meaning' is underdetermined as to the reference: the reference of a sign may vary even if the sign itself is fully determined. For example, the word fox may refer to any of thousands of thousands of particular foxes, both real and imagined, or possibly to the class of foxes, and so on. On the other side, in linguistic signs, the 'meaning' is relatively more determinate. Though the sound of the word fox, in principle, can be miscategorised as expressing another world rather than fox, this should be construed rather as a deviation.

$9 \quad$ See, e.g., Stjernfelt 1992, Kull 2002.

10 The reason why we don't want to construe the signified as the "meaning" is that the basic linguistic unit is the linguistic sign. It is the category to be recognised, and this is meant to be the "meaning" here.

11 A summary of the theory of reference in analytic philosophy can be found in Luure 2002. 
Now let us see how far we can extend this contrast. So we are to seek after the 'zero degree' and the 'full amount' of determinacy and indeterminacy, or, in other words, revealing and covering. The 'sign' reveals its 'meaning' fully precisely when it reveals nothing besides itself, i.e, when the 'sign' doesn't represent anything else beyond itself. This is the extreme case in the direction from reference to the properly linguistic realm. There can be no mistake, no deviation, when a 'sign' is to be its own 'meaning'. And on the other side, taken as such, this 'sign' gives no hint as to its further 'meaning' beyond its 'meaning' as the 'sign' itself. This zero degree of sign is what semioticians have not been willing to include in the class of signs, or, in the first place, any semiotic phenomena of all, because it seems to lack the defining characteristic of the sign, viz., the sign is to stand for something else. However, as we put it in the beginning: the 'sign' both uncovers and covers its 'meaning'; and here, both covering and uncovering have been lead to their maximum.

What is the other extreme? In religious contexts, words and phrases are sometimes taken to embody supernatural beings or other transcendent entities. If we take the word in question to be the 'sign' then its 'meaning' is fully present in the 'sign' as it is embodied there; on the other side, the 'sign' has no feature revealing any information about its 'meaning' as the transcendent meaning remains fully unknown in its embodiment. In contrast to the zero degree example, here the meaning is fully determinate from the side of the 'meaning', and the sign doesn't reveal anything at all from the side of 'sign'.

The complete list of the notches of the scale of meaning determinacy follows.

1. The first notch: the zero degree meaning. The idea of the zero degree of meaning enables us to exhaust the scale of meaning determinacy/indeterminacy. In speech and language, the zero degree signs are the elementary tokens ${ }^{12}$. They reveal no meaning beyond themselves, and so, on this elementary level, they cannot be compared to other tokens nor identified as belonging to types.

They cannot be remembered (in the ordinary sense of the word) at that level as non-zero degree memory requires more meaning than

12 We are using the usual type-token distinction as the distinction between general sorts of things (types) and their particular instances. In this particular example, the types are the linguistic signs. Correspondingly, we have in view the tokens of those signs rather than merely of, say, symbol strings. 
that: the memory of a zero degree sign is the sign itself. There is an intimate connection between memory and meaning: a sign can be remembered just through its meaning; so types of memory correspond to the types of meaning. The zero degree signs can be said to have no meaning precisely in the same sense as it can be said that they cannot be remembered.

The zero degree signs are, in themselves, the most perspicuous signs. There is nothing arbitrary in their 'meaning'. However, from the perspective of the opposite end of the scale, they are the most 'meaningless' signs.

The zero degree signs are necessary as the ultimate bearers of the signs of higher type.

2. The second notch: the repetitional meaning. The tokens, which were incomparable at the first level, now become comparable. The comparison takes place by means of 'cross-identifying' the tokens: different tokens are taken to be 'identical' as each other's continuations. However, this 'identity' doesn't involve any category; the identity is seen strictly in the framework of the actual chain of comparisons. The token compared to is the 'meaning' of the token compared.

In speech, this is realised in repeating the same token, as, e.g., the second token of the word 'in' in this sentence repeats the first token of this word. The repeating token is the 'meaning' of the token repeated. In ordinary speech, such repeating may take place on the purely phonological level, even if the semantical meaning is not understood.

This sign type is, as it were, halfway between tokens and types. Categorisation is still underway. The token still cannot be recognised as belonging to a category but only is associated with another token. The meaning (and memory) is retained until the chain is broken. In that chain, the 'sign'-'meaning' relation is reversible: the 'sign' also can be regarded as the 'meaning' of its 'meaning' ('backward repetition').

The 'meanings' of the second type should not be confused with references. Their existence is in a strong sense relational: they exist by the means of relations to other such 'meanings'. (The 'signs' themselves belong to those 'meanings'.) And the type they are heading for is the linguistic sign and not the reference. In contradistinction to references, the 'meanings' of second type are no independent existence but are constituted by their relations to 'signs'. 
The perspicuity of the repetitional signs is limited by the filter of the 'identity' criteria (such as phonology): only certain aspects of the token are chosen as relevant; this choice is external to the token itself. These aspects are chosen arbitrarily, though, of course, they are there in the 'signs'. Seen from the other side, the first rudiments of nonzero-degree 'meaning' are provided by the relations due to the 'identity' chain. True, the 'meaning' is not yet substantial as it boils down to the token relations where the (type) identity still is to be arisen.

3. The third notch: the categorial meaning. The identity proper of a (linguistic) unit arises only at that level. The scale as a whole reveals that, in its root, identity is the same thing as meaning. What arises as identity in the lower portion of the scale, further reveals itself as meaning. Categorisation is the first phase of the development of meaning.

The categorial 'meanings' are the categories the 'signs' are recognised to belong to. The 'signs' are perceived immediately as 'meanings'. The meanings are taken from a limited stock of possible meanings.

On this level, the memory of 'meaning' is independent from 'signs': it is realised by the categories. The 'sign'-'meaning' relation is irreversible.

Now the perspicuity of the 'sign' is still less than in the case of the referential meaning. The 'meaning' is attached to the 'sign' arbitrarily, and moreover, to the same 'sign' different meanings can be attached in the framework of one and the same language (homonymy). On the other hand, the identity, in the common sense of the word, here has been fully established, or, in the other words, the categorisation process has come to its end.

4. The fourth notch: the referential meaning. Here the 'signs' (referring expressions) and the 'meanings' (references) are mutually independent entities.

The next step of the development of meaning (and identity) leads to the main paradigm of the 'sign'-'meaning' relation where the sign stands for its meaning. Similarly to the second notch, we have here an external relation; however, in contrast to the repetitional meaning, the 'sign' and the 'meaning' are not constituted by this relation but the relation is, as it were, added to the 'sign' and the 'meaning'. The meanings are (the representations of) the entities of the extralinguistic 
world $^{13}$. Memory here is supported by the representations of the world.

The 'meanings' of the 'signs' depend on the circumstances of the world that are independent of the language. This makes the 'signs' even less perspicuous than the linguistic conventions do. On the other hand, language is regarded to be a universal description tool of the world. Everything conceivable (independently of language) can be expressed by means of language. This fills speech with meaning that reaches far longer than language.

5. The fifth notch: the poetical meaning. There is a further step to be taken in order for speech to become even more meaningful. Now we give up the restriction that the 'meaning' must be independent, and take the 'signs' to generate 'meanings' that are irreducible to entities independent from the signs. The 'signs' are in contact with things that are undescribable for us and yet are expressible by poetical 'signs'. In this expression, the 'sign' are expedient and every particular 'sign' is almost irreplaceable.

On the other hand, tiny changes can change the 'meaning' of the 'signs' drastically or even bereave them of meaning. Very little meaning is still retained in the 'signs' themselves. The memory is at the distance of a serious effort from us, demanding us to transcend our knowledge, i.e., our memory in the ordinary sense.

6. The sixth notch: the mystical meaning. Here the 'sign' is unperceivably a full embodiment of a (transcendent) 'meaning'. Besides the religious example's (in different doctrines such 'signs' may be God's names as God's incarnations, mantras as gods' incarnations, Holy Scripture as God's incarnation), in some cases a piece of inner speech may be construed as the embodiment of a thought having absolutely no understandable connection to the piece of speech.

The mystical 'signs' are the fully unconspicuous 'signs' because their 'meaning' is completely outside of what they are by themselves: they 'bear no sign' of their meaning. On the other hand, they are the best 'signs' in the sense that the 'meaning' is immediately present in them.

Memory stays beyond our reach; this also means that it is not our task to support memory, as this doesn't lie in our power.

13 The extralinguistic world involves both real and fictional things, and even the linguistic units as parts of the world. 


\section{The six types of referring}

Referring expressions are the 'signs' of their references as their 'meanings' 14 .

In the theory of reference in the analytical philosophy of language, there have been attempts to establish correspondences between the linguistic means of referring (the linguistic characteristics of the referring expressions) and the way of referring. Among the main linguistic types of linguistic expressions are demonstratives, proper names and nominal phrases (the latter construed as descriptions, especially definite descriptions, that is descriptions meant to specify a unique thing as its reference). For example, Kripke (1980) states that proper names (in their typical use) are rigid designators, i.e., they refer to one and the same object in every possible world, whereas definite descriptions are non-rigid designators, as their references in different possible worlds depend on the different circumstances in the different worlds ${ }^{15}$. Analogously, Donnellan (1966) distinguishes between the attributive use and the referential use of definite descriptions. In the attributive use, the description refers to whatever entity uniquely having the property specified by the description. In the referential use, the description refers to the object the user of the description thinks uniquely satisfies the description, even if doesn't do so. Different possible worlds and different beliefs can be treated in a uniform way, construing both as models (mental representations). Then both Kripke's and Donnellan's distinctions are distinctions between rigid and non-rigid uses of referring expressions. Below they are generalised.

The typology of referring follows the general schema of the example in the last section as follows. In each item of the typology, the unit of meaning goes through the same process of categorisation and the subsequent emergence of meaning from identity. This is one of the ways different typologies are woven into a uniform structure.

1. The first type of reference: demonstrative-like non-rigid reference. Sometimes demonstratives are used strictly deictically, i.e.,

14 More technical details and references can be found in Luure 2002.

15 For example, compare the sentence beginnings: "If Aristotle hadn't met Alexander..." and "If Alexander the Great's teacher hadn't met Alexander..." Instead of the rigid designator "Aristotle" we have the non-rigid designator in the second one. 
as referring expressions referring to a reference determined by the extralinguistic context regardless of both the content and the choice of the word. In principle, such use is possible for other expressions as well.

In this case, the categorisation of the unit of meaning (in this example, the reference) is only starting. The determination of the reference (i.e., the referring), is most abstract. The expression is indifferent to its reference. It cannot determine any characteristics of its reference besides its location (or something similar) and is not able to assure the retention of its reference; when repeated, the expression cannot establish the identity of the reference. Here the reference lies in the zero-degree notch.

2. The second type of reference: name-like rigid reference. This is the use Kripke (1980) attributes to proper names. The expression is meant to refer to a particular, determined entity, and subsequently the same expression is repeated and meant to refer to the same entity as did the expression repeated.

The categorisation of the reference is in process but it still doesn't come to its end. The expression cannot change the reference, once the reference is settled. The reference retains itself but, as a meaning, it has no identity in itself but its identity is dependent on the stipulation identity of reference in the act of referring. The reference lies in the repetitional notch.

3. The third type of reference: description-like non-rigid reference. Here referring is analogous to the non-rigid, attributive use of definite descriptions. The reference is determined as whatever entity uniquely satisfying the description. So the expression is insensitive to any replacement of the reference: no replacement spoils the act of referring since it is interested only in the unique satisfaction of the description.

This is the place where the categorisation is completed. But the category of the unit of meaning still is indifferent to the meaning proper, that is the referring proper. The reference lies in the categorial notch. Only the following notch brings us to the reference proper, so to say, to the referential reference.

4. The fourth type of reference: description-like rigid reference. In the beginning, the reference is determined via a definite description the reference is uniquely to satisfy, and further on, the reference is stipulated to be identical to the first one. This is the way a certain real 
unique identity is picked out in a way not depending on the circumstances of referring. In contrast to the second type of reference, the reference cannot be lost since it is anchored to the definite description.

What is happening now is analogous to the step from identity to meaning proper, i.e., from identity to referring. After the completion of the categorisation, the unit of meaning acquires its identity as independent from referring. The reference lies in the referential notch.

5. The fifth type of reference: name-like non-rigid reference. Let us take an example where the reference is still more independent from the expression so it takes again a name-like expression to catch it. Such necessity emerges when (fictional) references cannot be discriminated by means of their describable characteristics. Max Black (1952) imagines a world where there are only two totally similar ideally symmetric iron balls, Castor and Pollux. On these conditions we cannot know which is which, since there is no discriminating quality for them. Is then impossible to refer either to Castor or to Pollux? My suggestion is that we refer to them by means of their names, by means of which the references are generated and constituted. An analogous case is provided by abstract objects, say mathematical numbers: we can discriminate them only by their names.

Like in our first paradigm example 'signs' come to generate their 'meanings', here the referring expressions generate their meanings. The reference lies in the poetical notch.

6. The sixth type of reference: demonstrative-like rigid reference. Finally, when the references become entirely elusive and vitally important, the last means are expressions that resemble the demonstratives treated under the first item of this paradigm, except that they are rigid. Accordingly, the referring expression is not fully indifferent to its reference but is extremely interested of it. My example is again about the religious. Imagine that someone uses the referring expression God. Does this word refer to God or to Devil? We cannot catch the fact about this even by means of a name. In fact, these names function like demonstratives. The referring is a metaphysical fact but we don't have any sign to know this fact. And the reference of the same expression may differ according to situations. The expressions are rigid because the religious person really wants to refer to God, and not to Devil, however similar he may be to God. 
Here the reference lies in the mystical notch, since we here have full indeterminacy.

\section{Referring as a paradigm}

The examples in the previous sections are meant to be paradigms serving as keys to the whole structure. In this article we will not give more paradigms nor any analysis of sign typologies built on other principles. We showed on the example of the second paradigm how the first paradigm works. The categorisation of the unit of meaning and its further development is a universal for all sign typologies in this framework. Now we are going to show how referring can be a universal model for sign typologies.

The idea is that in all varieties of sign and meaning there is a determining relation which is a generalisation of the referring relation. Like in the case of referring the referring expression refers to the reference, in the general case the sign determines the meaning. This determination is not meant to be similar to causal determination. It has no necessity in the causal sense but is similar to the case of a mathematical function where the argument of the function determines the value of the function.

The key provided by the second paradigm leads us to construe the relation between the sign and the meaning in the fourth item as the relation of determination similar to referring. There that relation reveals itself in the clearest way. In the first paradigm this relation is the relation of referring. Further, the types of referring in the last section give an idea how the sign determines the meaning in the each particular item of the typology.

In the case of zero-degree meaning, the sign determines the meaning analogously to the first type of referring; in the case of repetitional meaning, the sign determines the meaning analogously to the second type of referring; etc.

\section{Beyond language}

The signs in the framework of speech and language are not the sole

signs. However, already in that framework we discovered strange 
varieties of signs and meaning, such as zero-degree meaning and repetitional meaning that are almost outside language. Now we are going to take a further step and expand the signs beyond the framework of language and speech, staying in the limits of human activity.

We will exemplify six types of achieving a certain location by means of a tool. The tool is the item that goes through its categorisation in the first three stages and consequently develops itself to its extreme indeterminacy.

1. I want to be on the Earth. Except for conceivable rare exceptions it is granted that I am on the Earth. I do n't have any identifiable tool for it, though almost anything around me and in myself is part of that tool.

2. I want to be in the next room. I just stand up and walk there. I don't give the task of relocating me to anybody else than myself. I don't have to fix up any particular tool because I need not give to myself signs that go much further from myself. Any part of walking is almost the same as doing something in order to walk.

3. In the elevator I push the button. Pushing the button is a tool that gets its meaning from its function. It doesn't try to take us anywhere and it has no goal at all. But it is a ready, categorised tool.

4. The fairy-tale fox who plays possum in order for the peasant to take it to his sleigh in the hope to get the fox's fur uses the type of meaning that people often use. Here tools are available precisely because we use others' goals. ${ }^{16}$

5. I take a taxi and tell the driver where I want to be. Only now we reached the level where our previous examples belong. Language allows us to generate a limitless amount of new meanings and directly to make my goals others' goals ${ }^{17}$. So the whole realm of language and speech gets located in a more general sign typology.

6. I am on a floating ice floe and I am praying for getting on land. This takes the tool out of myself completely. Praying is not really talking and also it is no action as I cannot $d o$ anything (in the previous item doing was reduced to saying).

16 In Grice's (1957) terms this corresponds to the 'natural meaning'.

7 Grice (1957) explains the emergence of this 'non-natural meaning' by the circumstance that I tell the address to the driver with the intention that he would drive me by means of recognising my intention. 
There is life and there are signs and meanings at each level but life gets more and more intensive, ultimately revealing itself in the extreme.

\section{Conclusion}

Complete sign typologies need zero-degree cases where the sign and the meaning can taken to coincide. They are justified by symmetry to their opposite extremes the importance of which seems to be clear.

Since everything contains this zero-degree meaning, it is natural for semiotic not to restrict its scope.

\section{References}

Augustine 397. De doctrina Christiana. An edition and English tradition: Green, R. P. H. (ed. and trans.) 1995. Augustine: De Doctrina Christiana. Oxford: Clarendon Press.

Black, Max 1952. The identity of indiscernibles. Mind 62: 153-164.

Donnellan, Keith S. 1966. Reference and definite descriptions. Philosophical Review 77: 281-304.

Eco, Umberto 1979. A Theory of Semiotics. Bloomington: Indiana University Press.

Grice, Paul 1957. Meaning. Philosophical Review 66: 377-388.

Kripke, Saul 1980. Naming and Necessity. Cambridge: Harvard University Press

Kull, Kalevi 2002. A sign is not alive — a text is. Sign Systems Studies 30(1): 327-336.

Kull, Kalevi; Emmeche, Claus; Favareau, Donald 2008. Biosemiotic questions. Biosemiotics 1(1): 41-55.

Luure, Andres 2001. Lessons from Uexküll's antireductionism and reductionism: A pansemiotic view. Semiotica 134(1/4): 311-322.

- 2002. Understanding life: Trans-semiotic analogies. Sign Systems Studies 30(1): 315-325.

- 2006a. Duality and Sextets: A New Structure of Categories. (Dissertationes Semioticae Universitatis Tartuensis 9.) Tartu: Tartu University Press.

- 2006b. The duality of understanding and the understanding of duality in semiotics. Sign Systems Studies 34(1): 67-81.

Peirce, Charles Sanders 1992 [1868]. On a new list of categories. In: Proceedings of the American Academy of Arts and Sciences 7: 287-298. Reprinted in: Houser, Nathan; Kloesel, Christian (eds.), The Essential Peirce: Selected Philosophical Writings, Vol. 1, 1-11. 
- 1998 [1903]. Nomenclature and divisions of triadic relations, as far as they are determined. In: Houser, Nathan; Kloesel, Christian (eds.), The Essential Peirce: Selected Philosophical Writings, Vol. 2, 289-299.

- 1998 [1908]. Excerpts from letters to Lady Welby. In: Houser, Nathan; Kloesel, Christian (eds.), The Essential Peirce: Selected Philosophical Writings, Vol. 2, 477-491.

Saussure, Ferdinand de 1959 [1916]. Cours de linguistique générale. Paris: Payot. English translation: Course in General Linguistics. New York: Philosophical Library.

Sebeok, Thomas A. 1986. I Think I Am a Verb. New York: Plenum.

Sebeok, Thomas A.; Umiker-Sebeok, Jean (eds.) 1992. Biosemiotics: The Semiotic Web 1991. Berlin: Mouton de Gruyter.

Stjernfelt, Frederik 1992. Categorical perception as a general prerequisite to the formation of signs? On the biological range of a deep semiotic problem in Hjelmslev's as well as Peirce's semiotics. In: Sebeok, Umiker-Sebeok 1992: 427-444.

- 2007. Diagrammatology: An Investigation on the Borderlines of Phenomenology, Ontology, and Semiotics. Dordrecht: Springer.

\section{Значения бывают вшестером}

Хотя кажется целесообразным ограничить сферу применения семиотики, для более полного понимания семиотических явлений необходимо осознать все мыслимые виды знака и значения. В статье вводится метод секстетов, на которым основывается единая шестеричная структура общих и специальных знаковых типологий. В качестве парадигм представляются общие типы и уровни знаков и значений в языке и речи и типы референции. В каждой знаковой типологии в рамках этой структуры категоризация, приводящая к единице значения, аналогична первым трем членам первой парадигмы и отношение между знаком и значением аналогично отношению референции.

\section{Tähendused käivad kuuekesi}

Kuigi semiootika rakendusvaldkonda tundub otstarbekas piirata, on semiootiliste nähtuste täielikumaks mõistmiseks vajalik välja tuua kõik mõeldavad märgi ja tähenduse tüübid. Artiklis tutvustatakse sekstettide meetodit, mis paneb aluse üldisemate ja erilisemate märgitüpoloogiate ühtsele kuueliikmelisele struktuurile. Paradigmadena esitatakse märkide 
ja tähenduste üldised tüübid ja tasemed keeles ja kõnes ning osutamise tüübid. Iga märgitüpoloogia puhul vaadeldakse tähendusühiku väljakategoriseerumist analoogiliselt esimese paradigma esimese kolme astmega ning märgi ja tähenduse vahelist suhet analoogiliselt osutamissuhtega. 